\title{
Differences in the Morphological Characteristics and Body Composition of Football Players in Montenegro
}

\author{
Marin Corluka \\ University of Mostar, Faculty of Mathematics and Science Education, Mostar, Bosnia and Herzegovina \\ Ivan Vasiljevic \\ University of Montenegro, Faculty for Sport and Physical Education, Niksic, Montenegro
}

\begin{abstract}
A B S T R A C T
The aim of this research was to determine the differences among the top football players of the two best Montenegrin club FC Sutjeska-Niksic and FC Budućnost-Podgorica in the morphological characteristics and body composition. A sample of 53 examinees is divided into two sub-samples. The first sub-sample of the examinees consisted of 23 players of FC Sutjeska-Niksic of the average age of $21.69 \pm 4.30$, the champions of the Cup of Montenegro in the season 2016/17, while the other sub-sample consisted of 30 players of FC Budućnost-Podgorica of the average age $22.73 \pm 4.33$, the champions of the Montenegrin Championship in the season 2016/17. Football players were tested immediately after the end of the competition season $2016 / 17$. Morphological characteristics in the body composition were evaluated by a battery of 11 variables: body height, body weight, waist size, triceps skin set, biceps skin set, back skin set, abdominal skin set, body mass index, fat percentage, muscle mass and bone mass. The standard central and dispersive parameters of all variables are calculated. The significance of the differences between the players of the top two football clubs in the morphological characteristics and variables for assessing body composition was determined by a t-test for independent samples. It was found that the football players of the two mentioned clubs have statistically significant differences by the variables that estimate the amount of subcutaneous fat tissue.
\end{abstract}

Key words: Football, Morphological Characteristics, Body Composition

\section{Uvod}

Za fudbalsku igru se kaže da je to najvažnija sporedna stvar na svijetu, okuplja velike mase na stadionima, kraj TV ekrana (Gardašević, 2010; Gardašević, Bjelica, Popović, \& Milašinović, 2016). To je je izuzetno dinamična i brza kolektivna igra, koja bogatstvom pokreta spada u red polistrukturalnih sportskih igara (Bjelica, 2005; Gardašević i Goranović, 2011; Gardašević i Bjelica, 2013; Gardaševic \& Bjelica, 2014a; Gardasevic i Bjelica, 2014b). Fudbal je sport koga odlikuju mnogobrojne i raznovrsne složene dinamičke kineziološke aktivnosti koje se odlikuju velikim brojem cikličnih (Gardašević, Vasiljević i Bojanić, 2015; Bjelica, Popović, \& Gardašević, 2016a; Bjelica, Popović i Gardašević, 2016b; Sermaxhaj, Popovic, Bjelica, Gardasevic, \& Arifi, 2017; Gardasevic, Bjelica \& Vasiljevic, 2017a; Gardasevic, Bjelica \& Vasiljevic, 2017b) i acikličnih kretanja (Gardasevic, 2015; Gardašević i sar., 2015; Gardašević, Bjelica i Vasiljević, 2016a; Gardašević, Bjelica i Vasiljević, 2016b; Gardasevic, Bjelica, Milasinovic i Vasiljevic, 2016; Gardaševic i Vasiljević, 2016; Gardasevic, Popovic, \& Bjelica, 2016). Vrhunski rezultati u fudbalu mogu se postići samo u uslovima programiranog trenažnog procesa (Gardašević, Bjelica i Popović, 2015). Od poznavanja strukture pojedinih antropoloških sposobnosti i karakteristika fudbalera, kao i njihovog razvoja, zavisi i kvalitetno upravljanje procesom sportskog treninga (Bjelica i Popović, 2012; Bjelica, 2013). Raznim istraživanjima treba utvrditi određene principe i zakonitosti transformacionih procesa antropoloških karakteristika bitnih za fudbal (Gardašević, Bjelica, Georgiev, \& Popović, 2012) a među njima naravno i morfolo- ških karakteristika. Saznanja o morfološkim karakteristikama važna su u kompleksnim sportskim igrama kao što je fudbal. Morfološki prostor definišu longitudinalna dimenzionalnost skeleta, transverzalna dimenzionalnost skeleta, masa i volumen tijela (Bjelica \& Fratrić, 2011). Svrha morfoloških karakteristika je da se poboljšaju vještine u mnogim sportovima (Carter \& Heath, 1990). Morfološki statusi vrhunskih sportista su relativno homogeni, zavisnosti od sporta, i mogu biti definisani kao modeli sportskog postignuća (Mišigoj-Duraković, Matković, \& Medved, 1995). Istraživanja morfoloških karakteristika među sportistima različitih sportova ukazuje na to da sportisti različitih sportova imaju svoja specifična obilježja. Mišićna masa poboljšava sportsko postignuće u aktivnostima koje zahtevaju mišićnu snagu i izdržljivost ali i u onima koje zahtijevaju zavidnu aerobnu sposobnost (Ramadan \& Byrd, 1987; Green, 1992; Rico-Sanz, 1998). Pripadnost sportiste jednoj sportskoj grani podrazumijeva njegov biotip, koji mu daje prednost da se bavi baš tim sportom u odnosu na druge.

Danas je fudbal sigurno sport broj jedan u svijetu po gledanosti i popularnosti (Gardašević, Georgiev \& Bjelica, 2012; Vasiljević, Gardašević, \& Bojanić, 2013), pa samim tim i u Crnoj Gori. Dva najveća kluba po tradiciji, popularnosti, bogatoj istoriji, broju osvojenih trofeja u ovoj zemlji su FK Sutjeska iz Nikšića i FK Budućnost iz Podgorice. Oni su u odigranoj takmičarskoj sezoni 2016/17. podijelili trofeje za osvojeno Prvenstvo (FK Budućnost) i za osvojeni Kup (FK Sutjeska), stekli pravo igranja na međunarodnoj fudbalskoj sceni u okviru takmičenja pod okriljem UEFA-e, pa su samim tim bili interesantni istraživačima oko utvrđivanja modelnih antropometrijskih karakteristika i njihovih međusobnih razlika. 
Cilj istraživanja je bio da se analiziraju razlike u pojedinim morfološkim karakteristikama između vrhunskih fudbalera ova dva Kluba.

\section{Metod}

Podaci dobijeni u istraživanju morfoloških karakteristika, kontrolisani su i pripremljeni za obradu u skladu sa postavljenim ciljem. Baze podataka su sređene po praćenim obilježjima i pripremljene za planiranu statističku obradu. Rezultati dobijeni statističkom obradom prikazani su u tabelama i analizirani po pripadajućim logičkim cjelinama. U cjelini posmatrano, prikaz rezultata istraživanja, kroz postupnost u obrazlaganju pojedinačnih veza, omogućava sagledavanje razlika u posmatranim morfološkim mjerama, u skladu sa ciljem istraživanja, odnosno doprinosi jasnom određenju prema očekivanoj primjeni dobijenih rezultata u praksi. U pogledu vremenske određenosti istraživanje je transverzalnog karaktera, a sastoji se u jednokratnom mjerenju odgovarajućih morfoloških karakteristika i sastava tijela vrhunskih fudbalera seniora.

\section{Uzorak ispitanika}

Uzorak ispitanika čini ukupno 53 vrhunska fudbalera seniorskog pogona koji nastupaju u Prvoj fudbalskoj ligi Crne Gore, podijeljen na dva subuzorka. Prvi subuzorak su činili 23 igrača FK Sutjeska-Nikšić, prosječne starosti $21.69 \pm 4.30$, osvajača Kupa Crne Gore u sezoni 2016/17., a drugi subuzorak su činili 30 igrača FK Budućnost-Podgorica, prosječne starosti $22.73 \pm 4.33$ godina, osvajača Prvenstva Crne Gore u sezoni 2016/17. Fudbaleri su testirani neposredno nakon okončanja takmičarske sezone 2016/17.

\section{Uzorak mjera}

Antropometrijsko istraživanje sprovedeno je uz poštovanje osnovnih pravila i principa vezanih za izbor mjernih instrumenata i tehnike mjerenja koji su standardizovani, prema upustvima Internacionalnog Biološkog Programa. Za potrebe ovog istraživanja izmjereno je 7 antropometrijskih mjera: visina tijela (ATV), težina tijela (ATM), obim struka (AOS), kožni nabor tricepsa (ANT), kožni nabor bicepsa (ANB), kožni nabor leđa (ANL), kožni nabor trbuha (ANS), i 4 varijable za procjenu sastava tijela: indeks tjelesne mase (BMI), procenat masti (APM), mišićna masa (AMM) i koštana masa (AKM). Za antropometrijsko mjerenje korišćeni su antropometar, kaliper i centimetarska traka. Za procjenu sastava tijela korišćena je tanita vaga, model BC-418MA. Princip rada ove vage je zasnovan na indirektnom mjerenju tjelesnog sastava, bezbjedan električni signal se šalje kroz tijelo preko elektroda smještenih u samostalnu jedinicu. Tanita vaga, zahvaljujući atletskom modu koje posjeduje, omogućava sportistima detaljno praćenje tjelesne težine, zdrastvenog stanja i kondicije, sa svim relevantnim parametrima.

\section{Metoda obrade podataka}

Podaci dobijeni istraživanjem obrađeni su postupcima deskriptivne i komparativne statističke procedure. Za svaku varijablu su obrađeni centralni i disperzioni parametri kao i mjere asimetrije i spljoštenosti Razlike u morfološkim karateristikama i sastavu tijela fudbalera ova dva Kluba utvrđene su primjenom diskriminativne parametrijske procedure, Studentovim t-testom za male nezavisne uzorke, sa statističkom značajnošću od $\mathrm{p}<0.05$.

\section{Rezultati}

U Tabelama 1 i 2 prikazani su osnovni deskriptivni statistički parametri antropometrijskih varijabli i sastava tijela fudbalera dva Kluba, gdje su izračunate vrijednosti mjera centralne i disperzione tendencije i to: aritmetička sredina (Mean), standardna devijacija (Std. Dev.), varijansa (Variance), minimalne (Min) i maksimalne (Max) vrijednosti, koeficijenti zakrivljenosti (Skewness) i izduženosti (Kurtosis). Prvo su analizirani centralni i disperzioni parametri varijabli za procjenu morfoloških karakteristika i sastava tijela igrača FK Sutjeska-Nikšić (Tabela 1.).

Tabela 1. Centralni i disperzioni parametri varijabli za procjenu antropometrijskih karakteristika i sastava tijela igrača FK Sutjeska-Nikšić

\begin{tabular}{|c|c|c|c|c|c|c|c|c|c|c|}
\hline & \multirow{2}{*}{$\mathbf{N}$} & \multirow{2}{*}{ Min } & \multirow{2}{*}{ Max } & \multirow{2}{*}{ Mean } & \multirow{2}{*}{ Std.D. } & \multirow{2}{*}{ Variance } & \multicolumn{2}{|c|}{ Skewness } & \multicolumn{2}{|c|}{ Kurtosis } \\
\hline & & & & & & & Stat. & Std. E. & Stat. & Std. E. \\
\hline ATV & 23 & 166.0 & 195.0 & 182.991 & 6.7696 & 45.828 & -.555 & .481 & .607 & .935 \\
\hline ATM & 23 & 68.0 & 91.7 & 78.326 & 7.7094 & 59.435 & .480 & .481 & -1.165 & .935 \\
\hline BMI & 23 & 21.7 & 25.8 & 23.361 & 1.4125 & 1.995 & .435 & .481 & -1.329 & .935 \\
\hline APM & 23 & 2.6 & 13.6 & 8.657 & 2.9212 & 8.533 & -.380 & .481 & -.512 & .935 \\
\hline AMM & 23 & 34.1 & 46.8 & 40.565 & 3.8087 & 14.506 & -.026 & .481 & -1.198 & .935 \\
\hline AKM & 23 & 2.7 & 5.0 & 3.383 & .5630 & .317 & 1.547 & .481 & 2.806 & .935 \\
\hline AOS & 23 & 76.0 & 90.0 & 83.000 & 3.8258 & 14.636 & .283 & .481 & -.540 & .935 \\
\hline ANT & 23 & 3.4 & 9.8 & 6.465 & 1.6648 & 2.771 & .262 & .481 & -.222 & .935 \\
\hline ANB & 23 & 3.1 & 7.7 & 4.522 & 1.2232 & 1.496 & 1.116 & .481 & .945 & .935 \\
\hline ANL & 23 & 6.4 & 11.8 & 8.130 & 1.4198 & 2.016 & 1.105 & .481 & 1.153 & .935 \\
\hline ANS & 23 & 5.4 & 14.0 & 8.248 & 2.3766 & 5.648 & .846 & .481 & .032 & .935 \\
\hline
\end{tabular}

$\mathrm{Na}$ osnovu centralnih i disperzionih parametara, vrijednosti skjunisa i kurtozisa možemo konstatovati da su sve varijable u granicama normalne raspodjele. Vidi se po vrijednosti skjunisa da tri varijable: koštana masa (AKM), nabor bicepsa (ANB) i nabor leđa (ANL) imaju blagu asimetriju, ne i statistički značajnu u stranu boljih rezultata iako imaju pozitivan predznak, jer je za fudbalere bitno da imaju manje vrijednosti potkožnog masnog tkiva i vrijednost koštane mase. Po vrijednosti kurtozisa se vide tri varijable tjelesna masa (ATM), indeks tjelesne mase (BMI) i mišićna masa koje imaju blagu platikurtičnost ne i sta- tistički značajnu, što znači da imamo različitih rezultata u ovim varijablama koji nijesu raspoređeni oko aritmetičke sredine, najvjerovatnije iz razloga da po linijama tima igrači (golmani, odbrana, vezni red i napadači) imaju različitu konstituciju i samim tim tjelesnu masu, što se i odrazilo na ove varijable. Vrijednost kurtozisa kod varijable koštana masa (AKM) pokazuje statistički značajnu izoštrenost i obrazuje leptokurtičnu krivu, što nam govori da je veliki broj rezultata u ovoj varijabli raspoređen oko aritmetičke sredine. Generalno, na osnovu svih statističkih parametara, može se konstatovati da se radi o vrhunskim 
fudbalerima, da u svim varijablama imamo normalan raspored i da preovladavaju rezultati bolji od aritmetičke sredine, ne i statistički značajnim jer je i za očekivati da kod fudbalera jednog profesionalnog kluba nema prevelikog raspona u rezultatima analiziranih varijabli. Tabela 2. prikazuje centralni i disperzione parametre varijabli za procjenu morfoloških karakteristika i sastava tijela igrača FK Budućnost-Podgorica.

Tabela 2. Centralni i disperzioni parametri varijabli za procjenu antropometrijskih karakteristika i sastava tijela igrača

\begin{tabular}{|c|c|c|c|c|c|c|c|c|c|c|c|}
\hline \multicolumn{12}{|c|}{ FK Budućnost-Podgorica } \\
\hline & \multirow[t]{2}{*}{$\mathbf{N}$} & \multirow[t]{2}{*}{ Range } & \multirow[t]{2}{*}{ Min } & \multirow[t]{2}{*}{ Max } & \multirow[t]{2}{*}{ Mean } & \multirow[t]{2}{*}{ Std.D. } & \multirow[t]{2}{*}{ Variance } & \multicolumn{2}{|c|}{ Skewness } & \multicolumn{2}{|c|}{ Kurtosis } \\
\hline & & & & & & & & Stat. & Std.E. & Stat. & Std.E. \\
\hline ATV & 30 & 24.9 & 171.1 & 196.0 & 181.960 & 5.8947 & 34.748 & .339 & .427 & -.260 & .833 \\
\hline ATM & 30 & 32.2 & 64.7 & 96.9 & 78.027 & 8.5221 & 72.627 & .730 & .427 & -.308 & .833 \\
\hline BMI & 30 & 6.0 & 21.1 & 27.1 & 23.487 & 1.4536 & 2.113 & .872 & .427 & .762 & .833 \\
\hline APM & 30 & 10.8 & 5.2 & 16.0 & 9.983 & 2.7626 & 7.632 & .160 & .427 & -.470 & .833 \\
\hline AMM & 30 & 12.2 & 34.7 & 46.9 & 39.543 & 3.6921 & 13.632 & .412 & .427 & -1.133 & .833 \\
\hline AKM & 30 & 1.2 & 2.7 & 3.9 & 3.203 & .3388 & .115 & .539 & .427 & -.537 & .833 \\
\hline AOS & 30 & 21.0 & 74.0 & 95.0 & 83.433 & 5.2304 & 27.357 & .454 & .427 & -.260 & .833 \\
\hline ANT & 30 & 9.6 & 4.0 & 13.6 & 7.787 & 2.4511 & 6.008 & .481 & .427 & -.274 & .833 \\
\hline ANB & 30 & 5.0 & 3.2 & 8.2 & 5.280 & 1.2989 & 1.687 & .540 & .427 & -.556 & .833 \\
\hline ANL & 30 & 15.0 & 3.6 & 18.6 & 9.807 & 2.8974 & 8.395 & .827 & .427 & 2.138 & .833 \\
\hline ANS & 30 & 11.8 & 6.4 & 18.2 & 10.220 & 2.9036 & 8.431 & 1.040 & .427 & .941 & .833 \\
\hline
\end{tabular}

Na osnovu centralnih i disperzionih parametara, vrijednosti skjunisa i kurtozisa, igrača FK Budućnost iz Podgorice, možemo konstatovati da su sve varijable u granicama normalne raspodjele i da su vrijednosti vrlo slične fudbalerima FK Sutjeska iz Nikšića. Takođe se može konstatovati da su u skoro svim varijablama kvantitativne vrijednosti bolje kod igrača FK Sutjeska-Nikšić, istina neznatno, međutim da li i statistički značajno to će pokazati komparativna statistička procedura, Studentov t-test (Tabela 3.). Po vrijednosti skjunisa vidi se da je kod varijable nabor trbuha
(ANS) došlo do male nagnutosti u stranu manjih rezultata što je dobro jer je potkožno masno tkivo remeteći faktor za profesionalne sportiste. Vrijednost kurtozisa kod varijable nabor leđa (ANL) obrazuje leptokurtičnu krivu i pokazuje statistički značajnu izoštrenost što nam govori da je veliki broj rezultata u ovoj varijabli raspoređen oko aritmetičke sredine. Da bi utvrdili da li ima statistički značajne razlike $u$ analiziranim varijablama kod vrhunskih fudbalera ova dva najbolja crnogorska Kluba primjenjena je statistička procedura t-test (Tabela 3.).

Tabela 3. Vrijednosti t-testa izmedju aritmetičkih sredina varijabli za procjenu antropometrijskih karakteristika i sastava tijela igrača FK Sutjeska-Nikšić i FK Budućnost-Podgorica

\begin{tabular}{|c|c|c|c|c|c|c|c|c|}
\hline Varijable & klub & $\mathbf{N}$ & Mean & Std. D. & Std. E. M. & t-test & Sig. & $\begin{array}{c}\text { Mean } \\
\text { Difference }\end{array}$ \\
\hline \multirow{2}{*}{ ATV } & SUT & 23 & 182.991 & 6.7696 & 1.4116 & \multirow{2}{*}{.592} & \multirow{2}{*}{.557} & \multirow{2}{*}{1.0313} \\
\hline & BUD & 30 & 181.960 & 5.8947 & 1.0762 & & & \\
\hline \multirow{2}{*}{ ATM } & SUT & 23 & 78.326 & 7.7094 & 1.6075 & \multirow{2}{*}{.132} & \multirow{2}{*}{.895} & \multirow{2}{*}{.2994} \\
\hline & BUD & 30 & 78.027 & 8.5221 & 1.5559 & & & \\
\hline \multirow{2}{*}{ BMI } & SUT & 23 & 23.361 & 1.4125 & .2945 & \multirow{2}{*}{-.316} & \multirow{2}{*}{.753} & \multirow{2}{*}{-.1258} \\
\hline & BUD & 30 & 23.487 & 1.4536 & .2654 & & & \\
\hline \multirow{2}{*}{ APM } & SUT & 23 & 8.657 & 2.9212 & .6091 & \multirow{2}{*}{-1.690} & \multirow{2}{*}{.097} & \multirow{2}{*}{-1.3268} \\
\hline & BUD & 30 & 9.983 & 2.7626 & .5044 & & & \\
\hline \multirow{2}{*}{ AMM } & SUT & 23 & 40.565 & 3.8087 & .7942 & \multirow{2}{*}{.985} & \multirow{2}{*}{.329} & \multirow{2}{*}{1.0219} \\
\hline & BUD & 30 & 39.543 & 3.6921 & .6741 & & & \\
\hline \multirow{2}{*}{ AKM } & SUT & 23 & 3.383 & .5630 & .1174 & \multirow{2}{*}{1.439} & \multirow{2}{*}{.156} & \multirow{2}{*}{.1793} \\
\hline & BUD & 30 & 3.203 & .3388 & .0619 & & & \\
\hline \multirow{2}{*}{ AOS } & SUT & 23 & 83.000 & 3.8258 & .7977 & \multirow{2}{*}{-.334} & \multirow{2}{*}{.739} & \multirow{2}{*}{-.4333} \\
\hline & BUD & 30 & 83.433 & 5.2304 & .9549 & & & \\
\hline \multirow{2}{*}{ ANT } & SUT & 23 & 6.465 & 1.6648 & .3471 & \multirow{2}{*}{-2.220} & \multirow{2}{*}{.031} & \multirow{2}{*}{-1.3214} \\
\hline & BUD & 30 & 7.787 & 2.4511 & .4475 & & & \\
\hline \multirow{2}{*}{ ANB } & SUT & 23 & 4.522 & 1.2232 & .2551 & 2160 & & \\
\hline & BUD & 30 & 5.280 & 1.2989 & .2371 & -2.160 & .036 & -.7583 \\
\hline $\mathrm{ANI}$ & SUT & 23 & 8.130 & 1.4198 & .2961 & 2546 & 014 & 16762 \\
\hline ANL & BUD & 30 & 9.807 & 2.8974 & .5290 & -2.546 & .014 & $-1.6 / 62$ \\
\hline ANS & SUT & 23 & 8.248 & 2.3766 & .4955 & 2646 & 011 & 10727 \\
\hline ANS & BUD & 30 & 10.220 & 2.9036 & .5301 & -2.646 & .011 & -1.9722 \\
\hline
\end{tabular}

Na osnovu dobijenih vrijednosti rezultata t-testa, može se primijetiti da postoje statistički značajne razlike kod četiri varijable na nivou značajnosti $\mathrm{p}<0.05$., i to sve četiri koje procjenjuju sastav tijela, a to su nabori ili vrijednosti potkožnog masnog tkiva. To su varijable nabor tricepsa (ANT), nabor bicepsa (ANB), nabor leđa (ANL) i nabor trbuha (ANS), gdje uvidom u poslednju kolonu (Mean difference) možemo konstatovati da fudbaleri FK Budućnost iz Podgorice imaju statistički značajno veću vrijednost potkožnog masnog tkiva od fudbalera FK Sutjeska iz Nikšića. Uvidom u ostale numeričke vrijednosti testiranih varijabli, može se konstatovati da fudbaleri FK Sutjeska iz Nikšića imaju neznatno bolje rezultate u većini ostalih tretiranih varijabli, međutim ne i statistički značajno. 


\section{Diskusija}

Cilj ovog istraživanja je bio, da se utvrdi razlika u antropometrijskim karakteristikama i sastavu tijela vrhunskih igrača dva najbolja fudbalska kluba u Crnoj Gori, osvajača dva moguća trofeja za prvenstvo i kup u takmičarskoj sezoni 2016/17. Uzorak od ukupno 53 ispitanika je podijeljen na dva subuzorka. Prvi subuzorak ispitanika su činili 23 igrača FK Sutjeska-Nikšić prosječne starosti $21.69 \pm 4.30$ osvajača Kupa Crne Gore u sezoni 2016/17., a drugi subuzorak su činili 30 igrača FK Budućnost-Podgorica prosječne starosti $22.73 \pm 4.33$ godina osvajača Prvenstva Crne Gore u sezoni 2016/17. Rezultati su dobijeni korišćenjem baterije od 11 testova u prostoru antropometrijskih karakteristika i sastava tijela. Uvidom u osnovne deskriptivne statističke parametre se može zaključiti da se radi o profesionalnim sportistima. Vidi se da su igrači oba kluba približnih srednjih vrijednosti analiziranih varijabli, što i ne čudi jer se radi o dva najbolja kluba u Crnoj Gori gdje je i koncentracija najboljih igrača najveća. Prosječna tjelesna visina oba kluba odgovoara i rezultatima istraživanja (Bjelica et al, 2012) gdje je ukupan broj stanovnika u Crnoj Gori među najvišim u Evropi, odnosno prosječne tjelesne visine od $183.2 \mathrm{~cm}$. Rezultati t-testa su pokazali postojanje statistički značajne razlike kod četiri varijable koje procjenjuju debljinu potkožnog masnog tkiva, pa se može zaključiti da igrači FK Sutjeska-Nikšić imaju značajno manje vrijednosti potkožnih nabora. Takođe, fudbaleri FK Sutjeska-Nikšić ima-

\section{R E F E R E N C E S}

Bjelica, D. (2005). Sistematizacija sportskih disciplina i sportski trening. Podgorica: Crnogorska sportska akademija.

Bjelica, D. (2013). Teorija sportskog treninga. Podgorica: Univerzitet Crne Gore.

Bjelica, D., \& Fratrić, F. (2011). Sportski trening: teorija, metodika i dijagnostika. Nikšić: Fakultet za sport i fizičko vaspitanje.

Bjelica, D., i Popović, S. (2012). Fudbal-teorija, tehnika i takti$k a$. Podgorica: Crnogorska sportska akademija.

Bjelica, D., Popovic, S., Kezunovic, M., Petkovic, J., Jurak, G., \& Grasgruber, P. (2012). Body Height and Its Estimation Utilizing Arm Span Measurements in Montenegrin Adults. Anthropological Notebooks, 18(2):69-83.

Bjelica, D., Popović, S., i Gardašević, J. (2016a). Modeli fizičke pripreme vrhunskih sportaša i doziranje opterećenja. Zbornik radova 14.godišnje međunarodne konferencije "Kondicijska priprema sportaša" (185-189), Zagreb: Udruga kondicijskih trenera Hrvatske.

Bjelica, D., Popović, S., i Gardašević, J. (2016b). Opći principi planiranja i programiranja fizičkih priprema sportaša. Zbornik radova 14.godišnje međunarodne konferencije "Kondicijska priprema sportaša” (190-192), Zagreb: Udruga kondicijskih trenera Hrvatske.

Carter, J.E.L., \& Heath, B.H. (1990). Somatotyping-Development and application. Cambridge, United Kingdom: Cambridge University Press.

Gardašević, J. (2010). Efekti programiranog rada u pripremnom periodu na transformaciju bazično-motoričkih $i$ situaciono-motoričkih sposobnosti kod fudbalera kadetskog uzrasta. Neobjavljena magistarska teza. Nikšić: Fakultet za sport i fizičko vaspitanje.

Gardašević, J., i Goranović, K. (2011). Efekti programiranog rada u pripremnom periodu na transformaciju eksplozivne snage kod fudbalera kadeta. Sport Mont, IX(28-30), 55-62. ju i manje vrijednosti potkožnih masti, $8.6 \%$ u odnosu na 9.9\% koliko imaju fudbaleri FK Budućnost iz Podgorice, a oba rezultata su u okvirima normativnih vrijednosti procenata masti koje iznose od 6-13\%. I kod skoro svih ostalih vrijednosti vidi se da bolje rezultate, međutim ne i statistički značajne, imaju fudbaleri FK Sutjeska iz Nikšića iako su osvojili manje vredniji trofej Kupa Crne Gore u odnosu na trofej za osvajača prvenstva koji je pripao fudbalerima FK Budućnost, istina u foto finišu prvenstva za korak ispred svog najvećeg rivala. $\mathrm{Na}$ osnovu dobijenih rezultata treneri FK Budućnost iz Podgorice mogu se bazirati na radu koji će omogućiti redukciju potkožnog masnog tkiva, i sigurno da će time svoje fudbalere napraviti još boljim i uspješnijim, jer je to remeteći faktor za fudbal. Treneri FK Sutjeska iz Nikšića mogu biti zadovoljni sa stanjem svojih igrača u pomenutim varijablama, međutim sigurno da i tu može doći do određenog poboljšanja. Takođe, u FK Sutjeska-Nikšić trebali bi se posvetiti i drugim istraživanjima i provjeriti stanje funkcionalno-motoričkog statusa, kao i taktičke obučenosti svojih igrača i analizirati da li tu leži razlog slabijeg rezultata u prvenstvenoj trci u odnosu na FK Budućnost. Rezultati koji su dobijeni ovim istraživanjem mogu poslužiti kao modelni parametri u procjenjivanim varijablama za sve ostale igrače fudbalskih klubova u Crnoj Gori, jer analizirani fudbaleri su najbolji i najuspješniji u Crnoj Gori po rezultatima i osvojenim trofejima i igraju za dva najveća, i po tradiciji i po veličini, kluba u državi.

Gardašević, J., Georgiev, G., \& Bjelica, D. (2012). Qualitative changes of basic motor abilities after completing a six-week training programme. Acta Kinesiologica, 6(1), 70-74.

Gardašević, J., Bjelica, D., Georgiev, G., \& Popović, S. (2012). Transformation of situational motor abilities with football players-cadets. Proceeding book, XVI International Scientific Congress "Olympic Sports and Sport for All" \& VI International Scientific Congress ,Sport, Stress, Adaptation” (373377), Sofia: National Sports Academy "Vassil Levski".

Gardašević, J., i Bjelica, D. (2013). Efekti programiranog trenažnog rada u trajanju od šest nedjelja na transformaciju fleksibilnosti kod fudbalera kadetskog uzrasta. Sport Mont, XI(37-39), 212-217.

Gardaševic, J., \& Bjelica, D. (2014a). The effects of the training in the preparation period on the dribbling speed with fifteen years old football players. Book of Abstracts of the 11th International Scientific Conference on Transformation Process in Sport "Sport Performance" (22-23), Podgorica: Montenegrin Sports Academy.

Gardasevic, J., i Bjelica, D. (2014b). Efekti rada u pripremnom periodu na brzinu vođenja lopte petnaestogodišnjih fudbalera. Sport Mont, XII(40-42), 160-166.

Gardašević, J., Vasiljević, I., \& Bojanić, D. (2015). Six-week preparation period and its effects on coordination transformation with football players under 16. Book of Abstracts 11th International Scientific Conference Management, Sport, Olympism (36), Beograd: Fakultet za menadžment u sportu, Alfa univerzitet.

Gardasevic, J. (2015). The effects of the training in the preparation period on the agility transformation with cadet level football players. Book of Abstracts of the 12th International Scientific Conference on Transformation Process in Sport "Sport Performance" (76-77), Podgorica: Montenegrin Sports Academy. 
Gardašević, J., Vasiljević, I., Bojanić, D., Muratović, A., Ljubojević, M., Milašinović, R., \& Bubanja, M. (2015). Sixweek Preparation Period and its Effects on Transformation Movement Speed with Football Players Under 16. Book of Abstracts, International Scientific Conference "Effects of Physical Activity Application to Anthropological Status with Children, Youth and Adults" (148), Belgrade:University of Belgrade: Faculty of Sport and Physical Education.

Gardašević, J., Bjelica, D., i Popović S. (2015). Efekti programiranog rada tokom pripremnog perioda na transformaciju agilnosti kod fudbalera kadetskog uzrasta. Sport Mont, XIII(43-45), 355-360.

Gardašević, J., Bjelica, D., \& Vasiljević, I. (2016a). Six-Week Preparation Period and its Effects on Transformation Movement Speed with Football Players Under 16. Sport Mont, 14(1), 13-16.

Gardašević, J., Bjelica, D., \& Vasiljević, I. (2016b). The Effects of the Training in the Preparation Period on the Repetitive Strength Transformation With Cadet Level Football Players. Book of Abstracts of the 13th International Scientific Conference on Transformation Processes in Sport "Sport Performance" (43), Podgorica: Montenegrin Sports Academy.

Gardasevic, J., Bjelica, D., Milasinovic, R., \& Vasiljevic, I. (2016). The Effects of the Training in the Preparation Period on the Repetitive Strength Transformation with Cadet Level Football Players. Sport Mont, 14(2), 31-33.

Gardaševic, J., \& Vasiljević, I. (2016). Effects of Preparation Period on Endurance in U16 Football Players. Book of $A b$ stracts of the $4^{\mathrm{TH}}$ International Scientific Conference "Exercise and Quality of Life" (108), Novi Sad: University of Novi Sad, Faculty of Sport and Physical Education.

Gardašević, J., Bjelica, D., Popović, S., \& Milašinović, R. (2016). Preparation Period and its Effects on the Speed of Ball Leading at Players U16. In Book of Summaries of 11th FIEP European Congress "Anthropological Aspects of Sport, Physical Education and Recreation" (30-31), Banjaluka: University of Banjaluka, Faculty of Physical Education and Sport.
Gardasevic, J., Popovic, S., \& Bjelica, D. (2016). After preparation period ball shooting accuracy at players U15. In $A b$ stract Book of the 8th Conference for Youth Sport (88), Ljubljana: University of Ljubljana, Faculty of Sport.

Gardasevic, J., Bjelica, D., \& Vasiljevic, I. (2017a). The strength of kicking the ball after preparation period with U15 football players. Book of Abstracts of the 14th International Scientific Conference on Transformation Processes in Sport "Sport Performance" (65-66), Podgorica: Montenegrin Sports Academy.

Gardasevic, J., Bjelica, D., \& Vasiljevic, I. (2017b). The Strength of Kicking the Ball after Preparation Period with U15 Football Players. Sport Mont, 15(2), 39-42.

Green, S. (1992). Anthropometric and physiological characteristics of south Australian soccer players. Australian Journal of Science and Medicine in Sport, 24, 3-7.

Mišigoj-Duraković, M., Matković, B., \& Medved, R. (1995). Morfološka antropometrija u športu. Morphological anthropometry in sports. Zagreb, Croatia: Fakultet za fizičku kulturu.

Ramadan, J., \& Byrd, R. (1987). Physical characteristics of elite soccer players. Journal of Sports Medicine and Physical Fitness, 27, 424-428.

Rico-Sanz, J. (1998). Body composition and nutritional assessments in soccer. International Journal of Sport Nutrition, 8, 113-123.

Sermaxhaj, S., Popovic, S., Bjelica, D., Gardasevic, J., \& Arifi, F. (2017). Effect of recuperation with static stretching in isokinetic force of young football players. Journal of Physical Education and Sport, 17(3), 1948-1953. doi: 10.7752/jpes.2017.03191

Vasiljević, I., Gardašević, J., i Bojanić, D. (2013). Uporedna analiza motoričkog prostora između aktivnih fudbalera kadetskog uzrasta i učenika srednje škole. Zbornik naučnih $i$ stručnih radova VI međunarodni simpozijum "Sport i zdravlje” (212-215), Tuzla: Fakultet za tjelesni odgoj i sport.

\author{
I. Vasiljevic \\ University of Montenegro, Faculty for Sport and Physical Education, Narodne omladine bb, 81400 Niksic, Montenegro \\ e-mail: vasiljevic.ivan301@gmail.com
}


